\title{
REVIEW
}

\section{Management of idiopathic epistaxis in adults: what's new?}

\author{
Il trattamento dell'epistassi idiopatica nell'adulto: cosa c'è di nuovo? \\ G. MECCARIELLO' ${ }^{1}$, C. GEORGALAS ${ }^{2}$, F. MONTEVECCHI ${ }^{1}$, G. CAMMAROTO ${ }^{13}$, R. GOBBI ${ }^{1}$, E. FIRINU1', \\ A. DE VITO ${ }^{1}$, C. VICINI ${ }^{1}$ \\ ${ }^{1}$ Department of Head-Neck Surgery, Otolaryngology, Head-Neck and Oral Surgery Unit, Morgagni Pierantoni \\ Hospital, Forli, Italy; ${ }^{2}$ Department of Otolaryngology, Hygeia Hospital, Athens, Greece \& Leiden University Hospital, \\ Leiden, The Netherlands; ${ }^{3}$ Department of Otolaryngology, University of Messina, Italy
}

\section{SUMMARY}

Epistaxis is one of the most common complaints presenting to emergency departments. The aim of this study is to systematically review and critically evaluate the evidence relating to treatment of idiopathic epistaxis for guiding best practice. A comprehensive review of the English language literature was performed using PubMed, Embase, Cochrane Library and Central electronic databases. The inclusion criteria were: retrospective or prospective or randomised controlled clinical trials which included outcomes in the management of idiopathic epistaxis. Twentythree articles met inclusion criteria and were reviewed. Nasal packing still represents the first-line approach to epistaxis, although, at present, it appears that there is clear evidence in the literature to suggest that it is less effective and associated with more admissions and longer hospital stays than endoscopic electrocoagulation-based management of epistaxis. In conclusion, cauterisation should be the first-line approach for its high cost-effectiveness rate and low risk of complications. Further research is urgently needed to assess the efficacy of new biomaterials.

KEY WORDS: Epistaxis $\bullet$ Protocol $\bullet$ Endoscopy $\bullet$ Cautery $\bullet$ Sphenopalatine artery $\bullet$ Embolisation

\section{RIASSUNTO}

L'epistassi è uno dei disturbi più comuni per il quale il paziente si rivolge spesso al pronto soccorso. Questa revisione della letteratura si propone di valutare sistematicamente e criticamente gli studi scientifici riguardo il trattamento dell'epistassi idiopatica al fine di ottenere utili spunti per la pratica clinica. La ricerca è stata eseguita nei database elettronici: PubMed, Embase, Cochrane e Central. I criteri di inclusione sono stati: studi clinici controllati retrospettivi o prospettici o randomizzati o studi su modelli animali che includevano $i$ risultati nella gestione dell'epistassi idiopatica. Sono stati individuati 23 articoli che soddisfano i criteri di inclusione. Il tamponamento nasale rappresenta ancora l'approccio di prima linea all'epistassi, anche se è evidente dalla letteratura che sia il meno efficace ma il più associato a ricoveri ospedalieri di maggior durata rispetto alla chirurgia endoscopica basata sull'elettrocoagulazione. In conclusione appare sempre più evidente che la cauterizzazione dovrebbe essere l'approccio di prima linea per l'alto tasso di costo-efficacia e il basso rischio di complicanze. Tuttavia, ulteriori ricerche urgenti sono necessarie per validare l'efficacia dei nuovi biomateriali nel trattamento dell'epistassi.

PAROLE CHIAVE: Epistassi $\bullet$ Endoscopia nasale $\bullet$ Cauterizzazione $\bullet$ Arteria sfenopalatina $\bullet$ Embolizzazione

\section{Introduction}

Epistaxis is one of the most common presenting symptom to both primary care and accident and emergency departments. It is thought to affect $10-12 \%$ of the population ${ }^{1}$, and although most cases are self-limiting, some do not resolve without intervention. Among these, $80 \%$ are from the Kiesselbach's plexus (anterior epistaxis) ${ }^{2}$. Interestingly, some studies have suggested a positive correlation between epistaxis and atmospheric pressure or relative humidity and changes in temperature ${ }^{34}$; others also included allergic rhinitis as one of the main causes of epistaxis ${ }^{5}$. Only $6 \%$ of patients with epistaxis will require medical assistance, and cases of severe intractable epistaxis are rare ${ }^{6}$. Anterior nasal packing, the most common therapy for epistaxis, has some limitations including potential for reduced ventilation and sleep apnoea, need for analgesics and, in some cases, need for prophylactic antibiotics ${ }^{6}$. Nasal cautery forms an important part of first line management, and is considered an important skill for anyone treating epistaxis ${ }^{7}$, but is unlikely to be practiced by non-otolaryngologists. The goal of this study was to assess current trends in the management of epistaxis in the adult population.

The aim of this study is to systematically review and critically evaluate the evidence relating to treatment of idiopathic epistaxis in order to guide best practice. 


\section{Search strategy}

A comprehensive review of the English language literature was performed using PubMed, Embase, Cochrane Library and Central electronic databases using the keyword "epistaxis". The search was executed in March 2016 and was limited exclusively to studies published after 2010. It yielded a total of 1917 articles. We retrieved the full text of any reports potentially meeting inclusion criteria and examined these independently to determine study eligibility. Articles were examined for data resolution with the intent to perform a meta-analysis. Different methods of metaanalyses were considered in reviewing the literature to seek results that would provide meaningful analysis with the least risk of introducing biases. The inclusion criteria were: retrospective or prospective or randomised controlled clinical trials which included outcomes in the management of idiopathic epistaxis. Exclusion criteria were case reports or letters/correspondence to editor; clinical studies including the management of epistaxis other than idiopathic or mixed cases in which was not possible to extrapolate data concerning idiopathic epistaxis; paediatric population or animal model; systematic reviews and meta-analyses; nonEnglish language manuscripts. To reduce the risk of incomplete literature search, a manual search of the references of included papers was performed (Fig. 1 for flowchart). Data from studies were first extracted and assessed by the principal investigator $(\mathrm{MG})$ and thereafter independently by 2 co-authors (MF and GC) using standardised data forms. Quality assessment of studies (QUADAS-2) tool was used to evaluate relevant study design characteristics of included studies ${ }^{8}$. A graphical display of QUADAS-2 results is shown in Figure 2.

\section{Results}

The search was performed in March 2016 and yielded 1,917 articles. Moreover, 2 records were added from a manual search. Twenty-three articles ${ }^{9-31}$ met inclusion criteria. An overview of included studies is included in Table I.

\section{Nasal packing}

The first-line therapy includes anterior-posterior synthetic nasal packs and balloons in most studies 9101718202123262731323435 . More specifically, the effectiveness of chitosan-based packing was assessed by Kourelis and Shikani ${ }^{24}$. Chitosan is a natural cationic polysaccharide with well-known powerful haemostatic properties. The study group consisted of 35 consecutive patients with drug-induced bleeding diathesis. The pack consisted of a single sheet of ChitoFlex ${ }^{\circledR}$ (Hemcon, Inc. Portland, OR,

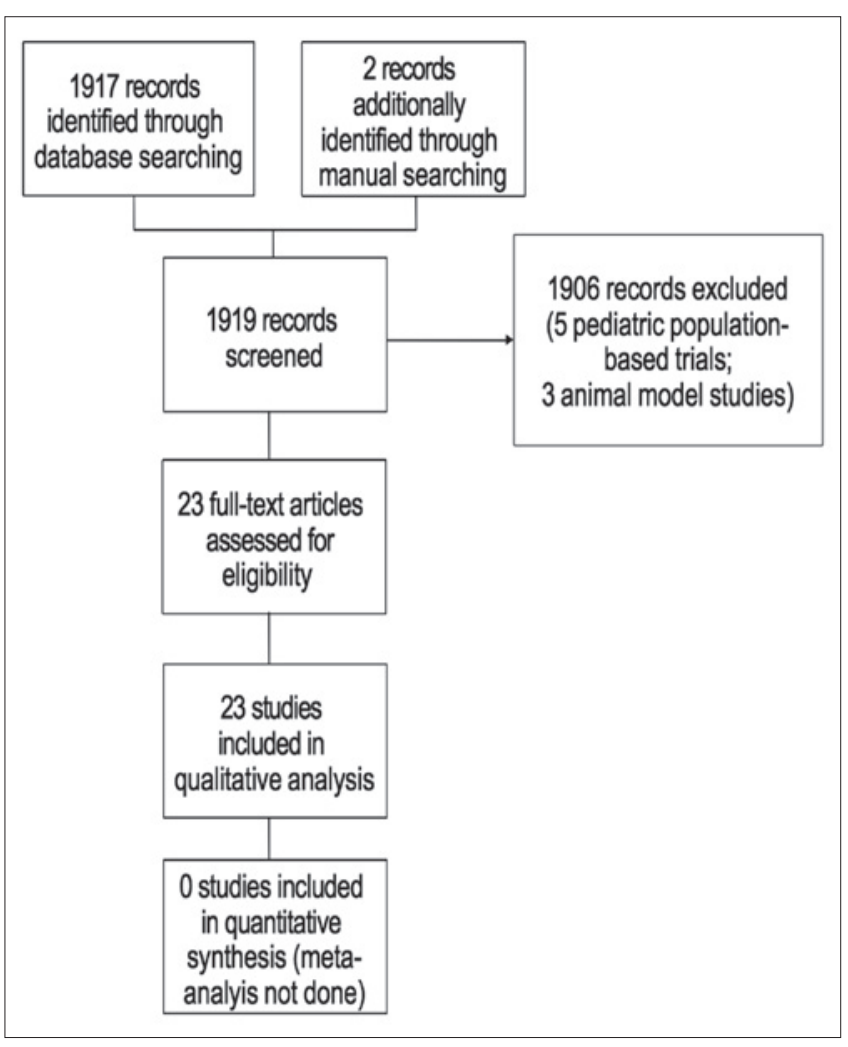

Fig. 1. Process for sifting search results and selecting studies for inclusion.

USA), wrapped around a hydroxylated polyvinylacetal sponge (Pope Merocel $^{\circledR}$, Medtronic, Inc, Minneapolis, MN, Usa). The chitosan-based nasal packing achieved instant control of bleeding in 32 cases $(91 \%)$. The mean time to bleeding cessation was $3.5 \mathrm{~min}$, ranging from 1 to $10 \mathrm{~min}$. Moreover, a comparison among different types of nasal packings was performed by Dutta et al. ${ }^{17}$. Three methods were included for the anterior nasal packing, nasal packing-merocel (group A), gauze pack lubricated by sisomicin ointment (group B) and the same gauze pack used with a splint made of a sterilised aluminium foil sheet prepared from the cover of the suture materials used over the septum (group C), carefully using the paper-covered surface of the foil to remain in contact with the mucosa to eliminate any systemic absorption of aluminium. In $26.7 \%(n=64)$, patients nasal tampon was used (30 for epistaxis and 34 for postoperative pack); $39.2 \%(n=94)$ of patients were treated with conventional gauze pack with sisomycin cream (60 for epistaxis and 34 for post operative pack). The remaining $34.2 \%(n=82)$ of patients were treated with the gauze pack with splint as described earlier (42 for epistaxis and 40 for postoperative pack). The "Behavioural Observational Pain Rating Scale" measured perception of pain during the procedure of packing. Fifty-six of 60 patients (93.33\%) with gauze packing for 


\section{QUADAS 2-DOMAIN}

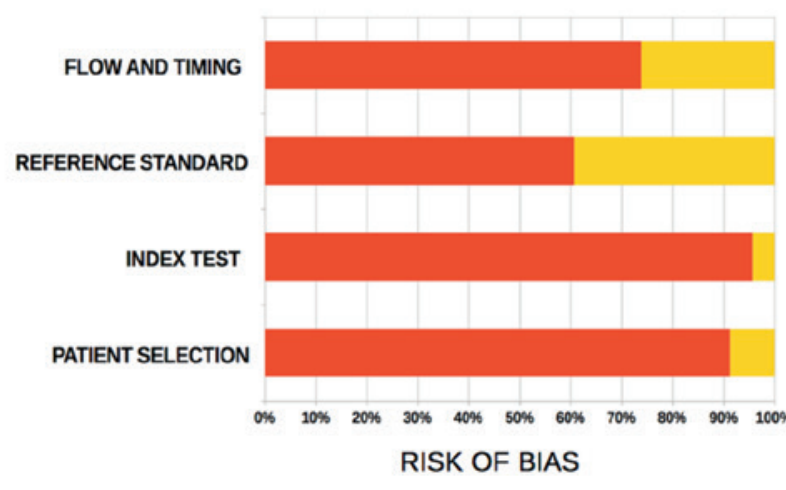

High $=$ Low anclear

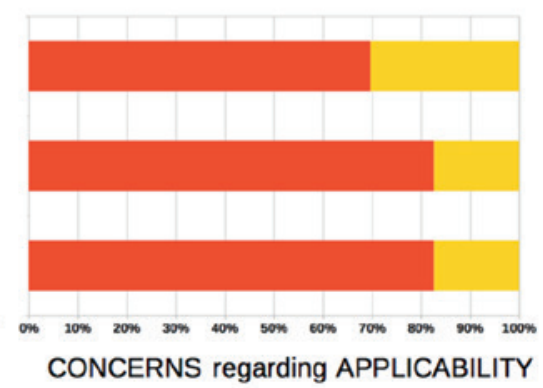

Fig. 2. Proportion of studies with unclear, low and high risk of bias and concerns regarding applicability.

Table I. Included studies.

\begin{tabular}{|c|c|c|c|c|c|c|}
\hline Authors & $\begin{array}{l}\text { Publication } \\
\text { year }\end{array}$ & $\begin{array}{l}\text { Study } \\
\text { design }\end{array}$ & $\begin{array}{c}\mathrm{N} \\
\text { of patients }\end{array}$ & $\begin{array}{l}\text { Site of } \\
\text { epistaxis }\end{array}$ & Materials & Outcomes \\
\hline Lau et al. ${ }^{9}$ & 2016 & $\begin{array}{l}\text { Prospective, } \\
\text { control- } \\
\text { matched, } \\
\text { longitudinal }\end{array}$ & $\begin{array}{c}20 \text { (cases) } \\
20 \text { (control group) }\end{array}$ & $\begin{array}{l}\text { Anterior and } \\
\text { posterior }\end{array}$ & FloSeal vs nasal packing & $\begin{array}{l}\text { FloSeal efficacy } 75 \% \text { vs nasal } \\
\text { packing } 85 \% \text { (NS) }\end{array}$ \\
\hline Zou et al. ${ }^{10}$ & 2015 & Retrospective & 53 & $\begin{array}{l}\text { Posterior fornix } \\
\text { of the inferior } \\
\text { nasal meatus }\end{array}$ & $\begin{array}{l}\text { Endoscopic bipolar electric } \\
\text { haemostat vs nasal packing }\end{array}$ & $\begin{array}{l}\text { Lower VAS score, rate of re- } \\
\text { bleeding, and nasal cavity } \\
\text { adhesion for endoscopic bipolar } \\
\text { electric haemostat }(p<0.001)\end{array}$ \\
\hline Limura et al. ${ }^{11}$ & 2015 & Retrospective & 167 & Posterior & $\begin{array}{l}\text { Electrocoagulation vs gauze } \\
\text { tamponade vs balloon tamponade } \\
\text { vs follow-up }\end{array}$ & $\begin{array}{l}\text { Recurrent bleeding rates } \\
\text { based were } 8.5 \% \text { (8/94) for } \\
\text { electrocoagulation, } 41.2 \%(21 / 51) \\
\text { for gauze tamponade, } 50 \%(1 / 2) \\
\text { for balloon tamponade, and } 45 \% \\
(9 / 20) \text { for follow-up }\end{array}$ \\
\hline Butrymowicz et al. ${ }^{12}$ & 2015 & $\begin{array}{l}\text { Anatomical } \\
\text { model and } \\
\text { prospective } \\
\text { case series }\end{array}$ & 4 & Anterior & $\begin{array}{l}\text { Endoscopic electrocautery greater } \\
\text { palatine artery }\end{array}$ & No recurrences \\
\hline Khan et al. ${ }^{13}$ & 2015 & Prospective & 101 & $\begin{array}{l}\text { Anterior and } \\
\text { posterior }\end{array}$ & FloSeal vs nasal packing & Success rate: $14 \%$ \\
\hline Kilty et al. ${ }^{21}$ & 2014 & Prospective & 20 & Posterior & FloSeal & Success rate: $80 \%$ \\
\hline Shrestha ${ }^{14}$ & 2014 & Retrospective & 12 & Posterior & Endoscopic sphenopalatine ligation & Success rate: $100 \%$ \\
\hline Henderson et al. ${ }^{15}$ & 2013 & Retrospective & 124 & $\begin{array}{l}\text { Anterior and } \\
\text { posterior }\end{array}$ & Electrocautery vs nasal packing & $\begin{array}{l}\text { The rates of admission and of } \\
\text { nasal packing reduced with } \\
\text { the increasing of usage of } \\
\text { electrocautery }(p<0.001)\end{array}$ \\
\hline Gandomi et al. ${ }^{16}$ & 2013 & Retrospective & 27 & Posterior & $\begin{array}{l}\text { Endoscopic sphenopalatine artery } \\
\text { ligation }\end{array}$ & Success rate $87 \%$ \\
\hline Gottumukkala et a.I ${ }^{18}$ & 2013 & Retrospective & 84 & Posterior & $\begin{array}{l}\text { Embolisation of one or more external } \\
\text { carotid artery branches }\end{array}$ & Success rate of $89 \%$ \\
\hline Zahed et al. ${ }^{19}$ & 2013 & $\begin{array}{l}\text { Randomised } \\
\text { controlled }\end{array}$ & $\begin{array}{l}109 \text { (anterior nasal } \\
\text { packing group) } \\
109 \text { (topical } \\
\text { tranexamic acid } \\
\text { group) }\end{array}$ & Anterior & $\begin{array}{l}\text { Anterior nasal packing vs topical } \\
\text { tranexamic acid }\end{array}$ & $\begin{array}{l}\text { Recurrence rates: } 11 \% \text { for anterior } \\
\text { nasal packing, } 2.8 \% \text { for topical } \\
\text { tranexamic acid }(p=0.018)\end{array}$ \\
\hline Shargorodsky et al 20 & 2013 & Retrospective & 147 & $\begin{array}{l}\text { Anterior and } \\
\text { posterior }\end{array}$ & $\begin{array}{l}\text { Nasal packing vs silver nitrate vs } \\
\text { dissolvable packing }\end{array}$ & $\begin{array}{l}\text { Failure rate } 23.8 \% \text { for silver } \\
\text { nitrate vs } 57.4 \% \text { for nasal packing } \\
\text { vs } 20 \% \text { dissolvable packing }\end{array}$ \\
\hline
\end{tabular}


Table I. follows.

\begin{tabular}{|c|c|c|c|c|c|c|}
\hline Authors & $\begin{array}{l}\text { Publication } \\
\text { year }\end{array}$ & $\begin{array}{l}\text { Study } \\
\text { design }\end{array}$ & $\begin{array}{c}\mathrm{N} \\
\text { of patients }\end{array}$ & $\begin{array}{l}\text { Site of } \\
\text { epistaxis }\end{array}$ & Materials & Outcomes \\
\hline Dutta et al. ${ }^{17}$ & 2012 & Prospective & 132 & Anterior & $\begin{array}{l}\text { Merocel vs gauze with sisomicin } \\
\text { cream vs gauze with sisomicin } \\
\text { cream and septal splint }\end{array}$ & $\begin{array}{l}\text { No recurrence rates after removal: } \\
96.9 \% \text { for Merocel, } 89.4 \% \text { for } \\
\text { gauze with sisomicin cream, } \\
97.6 \% \text { for gauze with sisomicin } \\
\text { cream and septal splint (NS) }\end{array}$ \\
\hline Mudunuri, Murthy 22 & 2012 & Prospective & $\begin{array}{l}42 \text { (conservative } \\
\text { group) } \\
52 \text { (silver nitrate } \\
\text { group) }\end{array}$ & Anterior & Silver nitrate vs conservative & $\begin{array}{l}\text { Failure rate: } 26 \% \text { for silver nitrate, } \\
30 \% \text { for conservative }\end{array}$ \\
\hline George at al. ${ }^{23}$ & 2012 & Retrospective & 25 & $\begin{array}{l}\text { Anterior and } \\
\text { posterior }\end{array}$ & $\begin{array}{l}\text { Endoscopic sphenopalatine artery } \\
\text { ligation }\end{array}$ & Success rate $88 \%$. \\
\hline Kourelis, Shikani ${ }^{24}$ & 2012 & Prospective & 35 & Anterior & Chitosan-based packing & Success rate: $91 \%$. \\
\hline Baloch et al. ${ }^{25}$ & 2012 & Retrospective & 16 & - & Angioembolisation & Success rate: $87.5 \%$ \\
\hline Zhang and Qiu ${ }^{26}$ & 2012 & $\begin{array}{l}\text { Randomised } \\
\text { controlled }\end{array}$ & $\begin{array}{l}41 \text { (Nd:YAG Laser) } \\
41 \text { (liquid paraffin } \\
\text { plus antiseptic } \\
\text { cream) }\end{array}$ & Anterior & $\begin{array}{l}\text { Nd:YAG laser vs liquid paraffin plus } \\
\text { antiseptic cream }\end{array}$ & $\begin{array}{l}\text { Success rate: } 85 \% \text { for Nd:YAG } \\
\text { laser vs } 40 \% \text { for control group }\end{array}$ \\
\hline Strach et al. ${ }^{29}$ & 2011 & Retrospective & 31 & - & $\begin{array}{l}\text { Endovascular embolisation with } \\
\text { polyvinyl alcohol particles }\end{array}$ & Long-term success rate: $93.5 \%$ \\
\hline Eladl et al. ${ }^{28}$ & 2011 & Prospective & 42 & Posterior & $\begin{array}{l}\text { Endoscopic sphenopalatine artery } \\
\text { ligation }\end{array}$ & Success rate: $100 \%$ \\
\hline Lesley et al. ${ }^{27}$ & 2010 & Retrospective & 20 & Posterior & $\begin{array}{l}\text { Angioembolisation with detachable } \\
\text { platinum fibered coils }\end{array}$ & Success rate: $95 \%$ \\
\hline Cotê et al. ${ }^{30}$ & 2010 & Prospective & 10 & Posterior & FloSeal & Success rate: $80 \%$ \\
\hline Minni et al. ${ }^{31}$ & 2010 & Retrospective & 48 & $\begin{array}{l}\text { Anterior and } \\
\text { posterior }\end{array}$ & $\begin{array}{l}\text { Endoscopic cautery of } \\
\text { sphenopalatine artery or anterior } \\
\text { ethmoidal artery }\end{array}$ & Success rate: $93 \%$ \\
\hline
\end{tabular}

epistaxis experienced severe pain (score 8-10), while 36 of $42(85.71 \%)$ experienced severe pain when aluminium foil splints were used. When nasal tampon was used, only 4 of 30 patients (13.33\%) felt severe pain. This difference was statistically significant. Obviously, pain could not be recorded if the packing was inserted under general anaesthesia during septal surgery. With gauze pack in situ, 22 of 34 patients $(64.70 \%)$ experienced moderate pain, in 6 patients $(17.65 \%)$ pain was mild and another 6 patients felt severe pain. With the addition of septal splint, 10 of 40 patients (25\%) felt mild pain, $28(70 \%)$ had moderate pain and 2 patients $(5 \%)$ experienced severe pain. Nasal tampon packing was almost painless in postoperative group as 30 of 34 patients $(88.23 \%)$ felt only mild pain. The episodes of bleeding while packed in situ, within first $48 \mathrm{~h}$ and forced for repacking, was significantly more prevalent among nasal tampon group (group A) of patients, but as such no difference was revealed between groups B and C. Regarding experience of bleeding after removal of packing, no difference could be observed between nasal tampon and gauze packing with or without splint. Whereas group B showed a significantly higher rate of bleeding compared to group C. Synaechia formation was not lower among group A patients; however, comparison with the other two groups showed that the event was more common among subjects who belonged to group B vs group $\mathrm{C}$, with a statistically significant difference.

\section{Electrocoagulation}

In other studies ${ }^{91017}$, the efficacy of nasal packing was compared to electrocoagulation. Zou et al. ${ }^{10}$ compared the outcomes between a group of 15 patients who underwent nasal packing for inferior meatus epistaxis and a group of 38 patients who had electrocoagulation using bipolar forceps both under general and local anaesthesia. The incidence of re-bleeding was significantly lower in the electrocoagulation group $(0 / 38)$ than in the packing group (4/15; $\mathrm{p}=0.001)$. Re-bleeding occurred within 48 and 24 hours after nasal pack removal in three and one patient, respectively. All patients with re-bleeding underwent endoscopic surgery with successful achievement of haemostasis. The discomfort visual analogue score (VAS) differed significantly between groups, ranging from 1 to 5 in the surgery group $(2.4 \pm 1.4)$ and 6 to 9 in the packing group $(7.6 \pm 1.0 ; \mathrm{p}=0.001)$. The incidence of nasal cavity adhesions was significantly lower in the surgery group $(2 / 38)$ than in the packing group $(7 / 15 ; p=0.007)$. Iimura et al. ${ }^{11}$ evaluated 167 patients with idiopathic 
posterior epistaxis. Bleeding sites included the olfactory cleft in 39 of 167 patients (23.4\%), middle meatus region in 44 patients $(26.3 \%)$, inferior meatus region in 36 patients $(21.6 \%)$, other in 8 patients $(4.8 \%)$ and unknown in 40 patients $(24.0 \%)$. Electrocoagulation was performed in 94 patients (56.3\%), gauze tamponade in 51 patients $(30.5 \%)$, balloon tamponade in 2 patients $(1.2 \%)$ and follow-up in 20 patients (12.0\%). Of note, electrocoagulation was performed using an endoscope in patients in whom electrocoagulation under direct vision was not possible. Monopolar forceps were used on bleeding sites where haemostasis using bipolar forceps (straight/ curved) was difficult. Recurrent bleeding occurred in 39 of 167 patients (23.4\%). The bleeding sites at initial examination in 39 patients with recurrent bleeding were the olfactory cleft, middle meatus and inferior meatus, in 6 , 8 and 4 patients, respectively, and was unknown in 21 patients. The recurrent bleeding rates based on bleeding site (patients with recurrent bleeding/patients with bleeding from the site) were $15.4 \%(6 / 39)$ for the olfactory cleft, $18.2 \%(8 / 44)$ for the middle meatus, $11.1 \%(4 / 36)$ for the inferior meatus and $52.5 \%(21 / 40)$ if the bleeding point was unknown. Haemostatic procedures at initial examination for 39 patients with recurrent bleeding were electrocoagulation $(n=8)$, gauze tamponade $(n=21)$, balloon tamponade $(\mathrm{n}=1)$ and follow-up $(\mathrm{n}=9)$. The recurrent bleeding rates based on the haemostatic procedure were $8.5 \%$ (8/94) for electrocoagulation, $41.2 \%$ (21/51) for gauze tamponade, $50 \%(1 / 2)$ for balloon tamponade and $45 \%(9 / 20)$ for follow-up, with electrocoagulation showing the lowest rate of recurrent bleeding.

Henderson et al. ${ }^{15}$ assessed the benefit of implementing a standardised treatment protocol for adult epistaxis management based upon the use of bipolar electrocautery in preference to nasal packing. The study compared the results of epistaxis treatment before and after introduction of the protocol. There were 61 and 63 individuals included in the pre- and post-protocol groups. The introduction of bipolar electrocautery as a treatment modality into the postprotocol group resulted in a significant change in treatment outcomes. The frequency of nasal packing reduced significantly from $34(56 \%)$ to $14(22 \%)(\mathrm{p}=0.0002)$, with a corresponding rise in bipolar electrocautery from nil to 27 (43\%) cases. The use of $\mathrm{AgNO}_{3}$ remained relatively constant between both groups, despite not being on the intervention protocol. Admission rates fell significantly between the two groups from 38 to $23(62-37 \%, p=0.0068)$. Admissions for social/medical reasons rose very slightly in the post-protocol group with an increase in social admissions $(5.7 \%)$. There were no cases recorded as readmissions. The overall average hospital length of stay was
1.2 days for the pre-protocol group, 0.83 days post-protocol and 2.4 days for those who underwent nasal packing in either group. Using actual numbers of overnight admissions, ward attenders and treatment used, total costs were $£ 24,706$ for the pre-protocol group, and $£ 18,175$ for the post-protocol group. This represented a per-patient average saving of $£ 117$, and per year $£ 43,345$ assuming an average of 31 presentations per month.

\section{FloSeal}

The usage of FloSeal haemostatic matrix (Baxter Healthcare, Deerfield, IL, USA), a human thrombin-impregnated, bovine gelatin matrix, has been evaluated in managing epistaxis alone ${ }^{2130}$ or compared to nasal packing ${ }^{913}$. Kilty et al. ${ }^{21}$ evaluated this matrix in 20 patients with posterior epistaxis. Gelatin-thrombin matrix successfully stopped posterior epistaxis in 16 cases (80\%). All of these cases received a single gelatin-thrombin matrix treatment. Four patients (20\%) required additional treatment after gelatinthrombin matrix failed to stop posterior epistaxis; two had surgical treatment; and two had posterior packing. No patient complications occurred in this study. Anticoagulant use was not significantly associated with treatment failure $(p=1.0)$. There was likewise no association with gender $(\mathrm{p}=0.58)$, hypertension $(\mathrm{p}=1.0)$, or diabetes $(\mathrm{p}=0.62)$. VAS assessment for pain with the gelatin-thrombin matrix treatment had a mean of 3.6. On the other hand, Côté et al. ${ }^{30}$ observed that epistaxis was adequately controlled in 8 of 10 patients without any adverse events. In Lau et al. ${ }^{9}$, nasal packing controlled epistaxis in 95\% (19/20) of patients. Eleven patients underwent packing with inflatable packs and 9 with nasal tampons. The individual who experienced immediate treatment failure had been packed with a nasal tampon and epistaxis was controlled after reinsertion of a second nasal pack. In the FloSeal group, epistaxis was controlled in 17 of 20 patients (85\%). Of the 3 patients who experienced immediate treatment failure, inflatable nasal packs controlled bleeding in 2 . When inflatable nasal packing also failed to control the remaining person's epistaxis, she underwent endoscopic sphenopalatine artery ligation. There were two readmissions within 7 days for both groups. The readmission rate was therefore $10 \%$ for both groups. Taking into account the readmission rate, the overall treatment success rate for nasal packing was 17 of 20 patients (85\%); it was 15 of 20 patients (75\%) for FloSeal. There was no significant difference between the primary outcomes for both groups $(\mathrm{p}=0.73)$. Conversely, Khan et al. ${ }^{13}$ evaluated FloSeal in 36 of 101 patients admitted for anterior and posterior epistaxis. The total success rate was $14 \%$ ( 5 of 36 cases). It was successful in 2 of 3 cases of anterior epistaxis (66\%) and in only 3 
of 33 cases of posterior epistaxis (9\%). Fisher's exact test indicated a significant difference in the success rates of FloSeal and nasal packing in the management of posterior epistaxis (9\% vs $92 \%$, respectively; $\mathrm{p}<0.001$ ).

\section{Tranexamic acid}

Zahed et al. ${ }^{19}$ conducted a trial to assess the efficacy of topical tranexamic compared to nasal packing. This randomised clinical trial study was conducted on 216 subjects (124 men and 92 women). Within 10 minutes of treatment, bleedings were arrested in $76(71 \%)$ of 107 patients in the tranexamic acid group, compared with $34(31.2 \%)$ of 109 patients in the anterior nasal packing group (odds ratio, 2.27; 95\% CI, 1.68-3.06; $\mathrm{p}<0.001$ ). In addition, $102(95.3 \%)$ of 107 patients in the tranexamic acid group were discharged in 2 hours or less vs 7 (6.4\%) of 109 patients in the anterior nasal packing group. Rebleeding was reported in 5 (4.7\%) of 107 and 14 (12.8\%) of 109 patients during the first 24 hours in the tranexamic acid and the anterior nasal packing groups, respectively $(\mathrm{p}=0.034)$. After 1 week, re-bleeding in the tranexamic acid and the anterior nasal packing groups were $2.8 \%$ and $11 \%$, respectively $(\mathrm{p}=0.018)$. Satisfaction rate was higher with tranexamic acid $(8.5 \pm 1.7)$ than with anterior nasal packing $(4.4 \pm 1.8)(\mathrm{p}<0.001)$.

\section{Silver nitrate}

Chemical cautery using the silver nitrate has also been investigated $^{2022}$. Chemical cautery was the most commonly used treatment modality for anterior epistaxis $(77.1 \%)$ in a cohort of 147 individuals ${ }^{20}$, and non-dissolvable packing was the most common intervention for posterior epistaxis (78.6\%). The failure rate was $23.8 \%$ for all patients undergoing chemical cautery. Among patients with anterior epistaxis who underwent chemical cautery, the failure rate was $21.0 \%$. All 3 patients who received chemical cautery for posterior epistaxis (posterior epistaxis cautery in the clinic is done with the use of an endoscope) all experienced treatment failure. The multivariate $\mathrm{OR}$ of failure was significantly higher for non-dissolvable packing than for chemical cautery $(6.08 ; 95 \% \mathrm{CI}, 2.17-17.09)$ in cases of anterior epistaxis. Of note, 4 patients underwent operative sphenopalatine ligation for their initial epistaxis episode. All of those patients had posterior bleeding that the surgeon believed was of high enough severity that it required a surgical intervention. Furthermore, Mudunuri and Murthy ${ }^{22}$ conducted a prospective study on 114 patients. Half of patients $(n=57)$ were managed using conservative treatment. The other half $(n=57)$ were treated with silver nitrate cautery of the bleeding points/prominent vessels. In the group treated conservatively, 30\% (13 cases) had at least one episode of epistaxis. In the group treated with cautery, 26\% (14 cases) had at least one episode of epistaxis. No statistical comparison was done.

\section{Endoscopic surgical procedures}

Butrymowicz et al. ${ }^{12}$ proposed an innovative surgical treatment to control recalcitrant anterior epistaxis based on anatomical dissections, computed tomography (CT) scan and small cohort of patients. The authors evaluated the feasibility and effectiveness of surgical ligation of the greater palatine artery endoscopically. They treated surgically, after careful cadaveric dissections and CT scan analyses, 4 patients with reasonable efficacy and feasibility of the procedure.

Shrestha ${ }^{14}$ described his personal results on 12 patients with epistaxis managed with endoscopical sphenopalatine artery ligation under general anaesthesia. Three of 12 patients developed synechia. However, the success rate in controlling epistaxis was $100 \%$.

George et al. ${ }^{23}$ investigated the efficacy sphenopalatine, anterior ethmoid and internal maxillary artery intervention in 25 patients. This series included 19 primary endoscopic sphenopalatine artery ligations, and three cases required adjuvant anterior ethmoid artery surgery. Exclusive anterior ethmoid artery ligation was done in two subjects and was indicated when a suspicious anterior bleed refractory to packing or cautery was present. One patient underwent embolisation of the internal maxillary artery because of high anaesthetic risk. Patients waited on average 1.9 days for the operating theatre whilst undergoing conservative management for epistaxis. The success rate for primary endoscopic sphenopalatine artery ligation surgery on the same admission was $89.4 \%$ (17/19). $80 \%$ (20/25) of patients had no further epistaxis episodes following their primary surgery, and so after discharge the overall success rate was $88 \%(22 / 25)$.

In a prospective study, Gandomi et al. ${ }^{16}$ endoscopically coagulated the sphenopalatine artery in 27 patients. Three patients required bilateral cauterisation. All operations involved cauterisation with bipolar diathermy. No patient suffered recurrent epistaxis within the first 24 hours of surgery (immediate post-op. period). Three patients suffered recurrent epistaxis within 2 weeks following surgery (early postop. period), two of whom needed anterior nasal packing with the third requiring no medical attention. One further patient had recurrent epistaxis within 7 days (early post-op. period) and also 2 months after surgery (late post-op. period). This patient further responded to conservative management including local cautery and anterior nasal packing. None of these four patients required any new surgical intervention. Therefore, the success rate was $87 \%$. Furthermore, in another prospective study, Eladl et al. ${ }^{28}$ showed a success 
rate of $100 \%$ and no recurrence of epistaxis in a cohort of 42 patients after endoscopic sphenopalatine cauterisation. Post-operative subjective evaluation of eye dryness indicated no dryness in $90.5 \%$ of patients $(n=38)$ and mild dryness in only $9.5 \%$ (four patients, who complained of mild eye burning and congestion). Objective evaluation of eye dryness (using Schirmer's test) was negative in all cases. Postoperative subjective evaluation of nasal dryness indicated that dryness was present in $81 \%$ of patients $(n=34)$, but was severe in only $9.5 \%(n=4)$, and resolved with medical treatment (i.e. nasal debridement and irrigation). Post-operative subjective evaluation for nasal sensation (i.e. para-aesthesia or hypoaesthesia of the nose, upper teeth and palate) indicated numbness and para-aesthesia of the upper teeth in three patients. Objective evaluation of nasal sensation found hypoaesthesia of the nasal mucosa in eight patients, but without any patient complaint. No hypoaesthesia of the hard palate was detected. No major post-operative complications or irreversible damage was encountered. Similar results, achieving the control rate of $93 \%$, were described in the study of Minni et al. ${ }^{31}$ (42 sphenopalatine artery and 6 anterior ethmoidal artery ligations).

\section{Endovascular embolisation}

Gottumukkala et al. ${ }^{18}$ reviewed their experience with routine multivessel embolisation for intractable idiopathic epistaxis in 84 patients and examined the association between the number of vessels receiving embolisation and treatment outcomes. Embolisation of bilateral internal maxillary artery (IMA) with or without facial artery embolisation was performed in 76 patients (41 with one or both facial arteries, 35 without facial artery). In cases where embolisation of three vessels was performed, the facial artery treated was always ipsilateral to the bleeding site. In 10 patients, it was unclear which side was the source of bleeding. Four of these patients received bilateral IMA and bilateral facial artery embolisation, whereas six received bilateral IMA embolisation alone. Successful treatment (no re-bleeding within 30 days) was achieved in 75 patients (89\%). Of the nine patients who had early re-bleeding, 6 experienced re-bleeding within 1 day of embolisation and did not require additional hospital admission. All nine patients required some form of retreatment, including surgical ligation of the ipsilateral anterior or posterior ethmoidal arteries $(n=6)$, endoscopic electrocautery $(n=4)$, and repeat embolisation $(n=1)$. There was one major complication (1\%). A patient who underwent bilateral IMA and bilateral facial artery embolisation experienced skin sloughing of the chin, submandibular pain and oedema that caused difficulty swallowing, and severe lip oedema with mild ulceration. The oedema, pain and ulceration subsided by 1-month follow-up; the skin sloughing resolved by 8 weeks. Minor complications occurred in 22 patients $(26 \%)$.

In another retrospective study ${ }^{25}, 16$ patients were evaluated. After embolisation, immediate cessation of bleed was achieved in all $16(100 \%)$ patients. However, in $2(12.5 \%)$ of cases angioembolisation had to be repeated; in 1 patient on the same day and in another patient after a month. Thus, the overall success rate was $87.5 \%$. In majority of cases $(56.25 \%)$, ipsilateral IMA was the bleeding source and was embolised.

Lesley et al. ${ }^{27}$ studied the efficacy and safety profile of detachable platinum fibered coil embolisation in a cohort of 20 patients. Seventeen patients underwent bilateral IMA embolisation. Three patients had unilateral IMA embosurgery of which two had previously undergone contralateral IMA open ligation for remote, but severe bouts of epistaxis. During the 30-day follow-up period, $95 \%$ of the cohort remained free of recurrent nose bleeding that required medical or surgical intervention. Open surgical anterior ethmoid cauterisation was needed to control bleeding in one patient $(5 \%)$ who re-bled 4 days after embosurgery. $95 \%$ of patients had no complications, while one patient $(5 \%)$ had short-lasting, transient unilateral facial pain.

Strach et al. ${ }^{29}$ evaluated 48 patients suffering from intractable epistaxis underwent angiography and selective intraarterial intervention. In this series, a total of 31 individuals presented with idiopathic epistaxis. The success rate after first-time embolisation was 29 of 31 (93.5\%). After ineffective unilateral embolisation of the sphenopalatine artery in one patient $(1 / 31 ; 3.2 \%)$, second-phase embolisation of the contralateral sphenopalatine, the descending palatine and branches of the facial artery, and, in a third phase, the ipsilateral sphenopalatine artery was performed, which finally lead to cessation of epistaxis increasing the success rate in group 1 to $96.8 \%$ (30/31). Despite bilateral embolisation of the sphenopalatine arteries, one patient $(1 / 31 ; 3.2 \%)$ had to undergo surgical coagulation of the ethmoidal artery to achieve haemostasis. One patient with initially successful unilateral embolisation of the sphenopalatine artery experienced reoccurrence of epistaxis after an asymptomatic period of 14 days and underwent additional septoplasty, thereby achieving haemostasis. Thus, the overall long-term success rate was $93.5 \%$.

\section{Laser}

Zhang and Qiu ${ }^{26}$ conducted a prospective, randomised, single-blinded study on the use of Nd:YAG laser for treatment of anterior epistaxis. A total of 80 consecutive patients were included and equally divided into Laser and ointment groups. After 12 weeks, $85 \%$ of laser patients 
and $40 \%$ of control patients had no reported bleeding. The outcome score of the 80 patients at 4 weeks after treatment showed no significant differences between groups (mean rank: 43.93 vs 37.08, ointment group versus laser group, $\mathrm{p}=0.130$ ). However, the outcome score at 12 weeks after treatment showed a significant difference between the two groups (mean rank: 49.60 vs 31.40, ointment group versus laser group, $\mathrm{p}<0.01)$. Neither experimental group had complications, such as blood transfusion, hospitalisation, visible nasal scars, nasal adhesions, or nasal septum perforation.

\section{Discussion}

The purpose of this study was to examine recent concepts in managing idiopathic epistaxis. Nasal packing still represents the first-line approach to epistaxis, although, at present, it appears that there is clear evidence in the literature suggesting that it is less effective and associated with more admissions and longer hospital stays than endoscopic electrocoagulation-based management of epistaxis. In $65 \%$ to $70 \%$ of cases of epistaxis, simple first aid measures provided by the primary care physician or emergency physician are effective. If bleeding persists, patients should be urgently referred to the ENT Department. So long as the source of the bleeding is visible, most cases of epistaxis can be successfully treated using electrical or chemical cautery. For posterior epistaxis, surgical intervention is markedly superior to packing. The method of choice is endoscopic clipping or coagulation of the sphenopalatine artery, which controls bleeding in $98 \%$ of cases ${ }^{32}$. Early sphenopalatine ligation has a cost-effective profile, while a randomised prospective trial of early ligation vs nasal packing found an overall costsavings of approximately \$ 7080. Additionally, the length of stay was less than half that for nasal packing. A 2003 retrospective study by Klotz et al. ${ }^{33}$ found that ligation had a mean length of stay of 2.1 days and \$ 3851 of associated costs. Moreover, Henderson et al. ${ }^{15}$ conducted an analysis on costs before and after application of a protocol teaching junior physicians on the use of cauterisation instead of nasal packing. They found a per-patient average saving of $£ 117$, and per year $£ 43,345$ assuming an average of 31 presentations per month. Its cost-effectiveness was also confirmed in the management of posterior epistaxis with endoscopic sphenopalatine ligation instead of traditional nasal packing. Dedhia et al. ${ }^{34}$ found, in the base case, costs for first-line endoscopic sphenopalatine ligation and current practice (nasal packing) arms were \$ 6450 and \$ 8246, respectively. In other words, there was a cost savings of \$ 1796 in the firstline endoscopic sphenopalatine ligation arm.

On the other hand, endovascular interventions are an important option for the treatment of life-threatening posterior epistaxis. Percutaneous embolisation is highly efficient and its safety profile compares favourably with alternative therapeutic modalities. It is noteworthy that, unlike other treatment strategies, major complications, such as cerebrovascular embolism or soft-tissue damage, may occur. Hence, this approach should be the last option and to be used only when all other options fail or in the presence of severe comorbidities that might preclude general anaesthesia ${ }^{35}$.

Finally, data concerning the use of drugs (i.e. tranexamic acid) or other medical devices did not show a substantially stronger clinical applicability. This is due to the fact that the data are extrapolated from few studies usually with a small cohort of patients, and most are neither randomised nor comparative.

\section{Conclusions}

Currently, the most common first-line treatment of idiopathic epistaxis is nasal packing, although there is a clear trend away from the use of nasal packs. Although it is a quick and easy to learn technique, emerging evidence show that cauterisation provides economic advantages and is easy to teach, especially for anterior epistaxis, to non-otolaryngologists. Early sphenopalatine artery ligation should also confer financial advantages, while the use of endovascular techniques should be reserved as a last option. Further research is urgently needed to assess the efficacy of new biomaterials that might have a significant impact on first-line management.

\section{Conflict of interest statement}

None declared.

\section{References}

1 Rockey JG, Anand R. A critical audit of the surgical management of intractable epistaxis using sphenopalatine artery ligation/diathermy. Rhinology 2002;40:147-9.

2 Al Khtoum N, Al Roosan M. The evaluation of conservative measures in the treatment of epistaxis. Khartoum Med J 2008;1:15-7.

3 Bray D, Giddings CE, Monnery P, et al. Epistaxis: are temperature and seasonal variations true factors in incidence? J Laryngol Otol 2005;119:724-6. https://doi.org/10.1258/0022215054798032.

4 Comelli I, Vincenti V, Benatti M, et al. Influence of air temperature variations on incidence of epistaxis. Am J Rhinol Allergy 2015;29:175-81. https://doi.org/10.2500/ajra.2015.29.4176.

5 Purkey MR, Seeskin Z, Chandra R. Seasonal variation and predictors of epistaxis. Laryngoscope 2014;124:2028-33. https://doi. org/10.1002/lary.24679.

6 Bertrand B, Eloy P, Rombaux P, et al. Guidelines to the management of epistaxis. B-ENT 2005;Suppl 1:27-41.

7 Ho EC, Chan JY. Front-line epistaxis management: let's not forget the basics. J Laryngol Otol 2008;122:696-9. https://doi.org/10.1017/ S0022215108002181. 
8 Whiting PF, Rutjes AW, Westwood ME, et al. QUADAS-2: a revised tool for the quality assessment of diagnostic accuracy studies. Ann Intern Med 2011;155:529-36. https://doi.org/10.7326/0003-4819155-8-201110180-00009.

9 Lau AS, Upile NS, Lazarova L, et al. Evaluating the use of Floseal haemostatic matrix in the treatment of epistaxis: a prospective, control-matched longitudinal study. Eur Arch Otorhinolaryngol 2016;273:2579-84. https://doi.org/10.1007/s00405-016-3948-y.

10 Zou Y, Deng YQ, Xiao CW, et al. Comparison of outcomes between endoscopic surgery and conventional nasal packing for epistaxis in the posterior fornix of the inferior nasal meatus. Pak J Med Sci 2015;31:1361-5. https://doi.org/10.12669/pjms.316.8340.

11 Iimura J, Hatano A, Ando Y, et al. Study of hemostasis procedures for posterior epistaxis. Auris Nasus Larynx 2016;43:298-303. https://doi.org/10.1016/j.anl.2015.09.015.

12 Butrymowicz A, Weisstuch A, Zhao A, et al. Endoscopic endonasal greater palatine artery cauterization at the incisive foramen for control of anterior epistaxis. Laryngoscope 2016;126:1033-8. https://doi.org/10.1002/lary.25677.

13 Khan MK, Reda El Badawey M, Powell J, et al. The utility of FloSeal haemostatic agent in the management of epistaxis. J Laryngol Otol 2015;129:353-7. https://doi.org/10.1017/S0022215115000663.

14 Shrestha BL. Endoscopic sphenopalatine artery cauterization in recurrent posterior epistaxis: an experience at Dhulikhel Hospital, Kathmandu University Hospital. Kathmandu Univ Med J (KUMJ) 2014;12:85-6.

15 Henderson AH, Larkins A, Repanos C. The use of bipolar electrocautery in adult epistaxis management: using audit of one hundred and twenty-four cases to define a standardised protocol. Clin Otolaryngol 2013;38:554-8. https://doi.org/10.1111/coa.12191.

16 Gandomi B, Arzaghi MH, Khademi B, et al. Endoscopic cauterization of the sphenopalatine artery to control severe and recurrent posterior epistaxis. Iran J Otorhinolaryngol 2013;25:147-54.

17 Dutta S, Mukherjee A, Saha J, et al. Modified technique of anterior nasal packing: a comparative study report. Indian J Otolaryngol Head Neck Surg 2012;64:341-5. https://doi.org/10.1007/s12070-011-0343-2.

18 Gottumukkala R, Kadkhodayan Y, Moran CJ, et al. Impact of vessel choice on outcomes of polyvinyl alcohol embolization for intractable idiopathic epistaxis. J Vasc Interv Radiol 2013;24:234-9. https:// doi.org/10.1016/j.jvir.2012.10.001.

19 Zahed R, Moharamzadeh P, Alizadeharasi S, et al. A new and rapid method for epistaxis treatment using injectable form of tranexamic acid topically: a randomized controlled trial. Am J Emerg Med 2013;31:1389-92. https://doi.org/10.1016/j.ajem.2013.06.043.

20 Shargorodsky J, Bleier BS, Holbrook EH, et al. Outcomes analysis in epistaxis management: development of a therapeutic algorithm. Otolaryngol Head Neck Surg 2013;149:390-8. https://doi. org/10.1177/0194599813492949.

21 Kilty SJ, Al-Hajry M, Al-Mutairi D, et al. Prospective clinical trial of gelatin-thrombin matrix as first line treatment of posterior epistaxis. Laryngoscope 2014;124:38-42. https://doi.org/10.1002/ lary. 24240.
22 Mudunuri RK, Murthy MA. The treatment of spontaneous epistaxis: conservative vs cautery. J Clin Diagn Res 2012;6:1523-4. https:// doi.org/10.7860/JCDR/2012/4215.2548.

23 George A, Smatanova K, Joshi $\mathrm{H}$, et al. Sphenopalatine, anterior ethmoid and internal maxillary artery intervention in the management of refractory epistaxis: their efficacy in 25 patients. Clin Otolaryngol 2012;37:321-5. https://doi.org/10.1111/j.17494486.2012.02499.x.

24 Kourelis K, Shikani AH. Effectiveness of chitosan-based packing in 35 patients with recalcitrant epistaxis in the context of coagulopathy. Clin Otolaryngol 2012;37:309-13. https://doi.org/10.1111/ j.1749-4486.2012.02488.x.

25 Baloch MA, Awan MS, Resident HN. Angioembolization in intractable epistaxis - a tertiary care experience. J Pak Med Assoc 2012;62:254-6.

26 Zhang J, Qiu R. A prospective randomised controlled trial of Nd:YAG laser photocoagulation versus liquid paraffin plus antiseptic cream in the treatment of recurrent epistaxis. Clin Otolaryngol 2012;37:271-5. https://doi.org/10.1111/j.1749-4486.2012.02509.x.

27 Lesley WS, Rangaswamy R, Patel DV. Results of epistaxis embosurgery using detachable platinum fibered coils. J Neurointerv Surg 2010;2:171-5. https://doi.org/10.1136/jnis.2009.001834.

28 Eladl HM, Elmorsy SM, Khafagy YW. Endoscopic devascularisation of sphenopalatine bundle in intractable posterior epistaxis: technique, efficacy and safety. J Laryngol Otol 2011;125:1136-40. https://doi.org/10.1017/S0022215111002180.

29 Strach K, Schröck A, Wilhelm K, et al. Endovascular treatment of epistaxis: indications, management, and outcome. Cardiovasc Intervent Radiol 2011;34:1190-8. https://doi.org/10.1007/s00270-0110155-5.

30 Côté D, Barber B, Diamond C, et al. FloSeal hemostatic matrix in persistent epistaxis: prospective clinical trial. J Otolaryngol Head Neck Surg 2010;39:304-8.

31 Minni A, Dragonetti A, Gera R, et al. Endoscopic management of recurrent epistaxis: the experience of two metropolitan hospitals in Italy. Acta Otolaryngol 2010;130:1048-52. https://doi. org/10.3109/00016481003621538.

32 Beck R, Sorge M, Schneider A, et al. Current approaches to epistaxis treatment in primary and secondary care. Dtsch Arztebl Int 2018;115:12-22. https://doi.org/10.3238/arztebl.2018.0012.

33 Klotz DA, Winkle MR, Richmon J, et al. Surgical management of posterior epistaxis: a changing paradigm. Laryngoscope 2002;112:1577-82. https://doi.org/10.1097/00005537-20020900000008 .

34 Dedhia RC, Desai SS, Smith KJ, et al. Cost-effectiveness of endoscopic sphenopalatine artery ligation versus nasal packing as firstline treatment for posterior epistaxis. Int Forum Allergy Rhinol 2013;3:563-6. https://doi.org/10.1002/alr.21137.

35 Goddard JC, Reiter ER. In patient management of epistaxis: outcomes and cost. Otolaryngol Head Neck Surg 2005;132:707-12. https://doi.org/10.1016/j.otohns.2005.02.001.

Received: March 18, 2018 - Accepted: May 27, 2018

How to cite this article: Meccariello G, Georgalas C, Montevecchi F, et al. Management of idiopathic epistaxis in adults: what's new? Acta Otorhinolaryngol Ital 2019;39:211-219. https://doi.org/10.14639/0392-100X-2155

Address for correspondence: Giuseppe Meccariello, Department of Head-Neck Surgery, Otolaryngology, Head-Neck and Oral Surgery Unit, Morgagni Pierantoni Hospital, via Carlo Forlanini 34, 47100 Forlì, Italy. E-mail: drmeccariello@ gmail.com 